\title{
Lower growth rate for drug spending
}

$\mathrm{T}$ he growth rate of spending on drugs in Canada has reached a 14-year low, according to a new report from the Canadian Institute for Health Information (CIHI). In 2010, Canada spent an estimated $\$ 31.1$ billion on drugs, a $4.8 \%$ increase from the year prior. That growth rate is a little more than half the rate of annual growth between 2000 and 2005 .

"It's a positive sign that costs are starting to come down, but we don't know for sure what the future holds as to whether this trend will continue or not," says Michael Gaucher, CIHI's manager of pharmaceuticals. "Drugs play an important role for Canadians in treating various conditions, particularly for seniors with chronic conditions,"

One reason spending on drugs is decreasing is that many expensive blockbuster products have come off patent, and pharmaceutical companies are struggling to fill their pipelines with new offerings that hold the potential for billion-dollar sales.

As a result, generic drugs are being prescribed in ever-growing numbers. Provincial government policies to reduce how much money pharmacies receive for those generic drugs have also contributed to lowering the country's overall pharmaceutical expenditure.

"Those two forces could, potentially, continue this trend of lowering drug expenditure," says Gaucher. "Then again, we are only a few blockbusters away from a higher expenditure."

There are also other factors that influence spending on drugs in Canada, according to the report, Drug Expenditure in Canada, 1985 to 2010 (http ://secure.cihi.ca/cihiweb/products/drug _expenditure_2010_en.pdf).

"Since drug prices, as measured by several price indices, have been relatively stable over the past 10 years, factors affecting increased drug spending in Canada essentially relate to the volume of drug use and the entry of new drugs (typically introduced to the market at higher prices)," the report states.

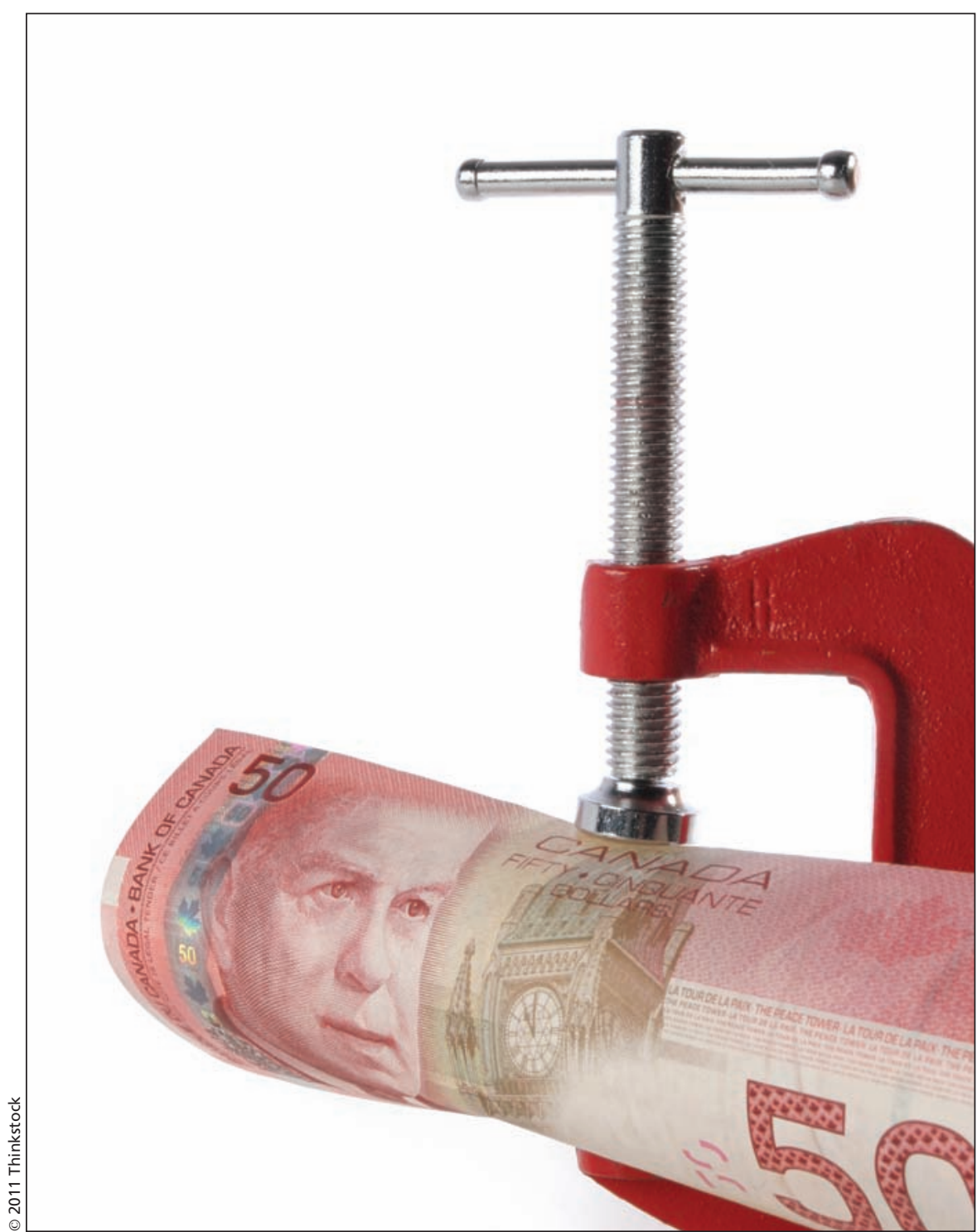

Efforts to squeeze the growth rate of spending on generics have had an effect but pharmaceutical spending in Canada nevertheless continues to rise.

Additional factors that could affect drug expenditure include inflation, new government regulations, demographic changes, emergence of new diseases or epidemics, additions to provincial drug formularies, adoption of preventive health strategies and access to drug insurance. "In general, the more accessible and more generous insurance coverage is, the less costly drugs are to the end consumer and the more likely people are to consume drugs," states the report.
Though the growth of spending on drugs is slowing, drug expenditure still accounts for the second-largest chunk of total health care spending, exceeded only by spending on hospitals. In 2008, $16.3 \%$ of health care dollars were spent on pharmaceuticals. Per capita spending on drugs jumped from $\$ 147$ per Canadian in 1985 to an estimated $\$ 912$ in 2010.

That amount varied significantly, however, across the provinces and terri- 
tories. At $\$ 574$, per capita spending on drugs in Nunavut in 2010 was the lowest in Canada, followed by spending in the Northwest Territories, where \$644 worth of products claimed space in the average resident's medicine cabinet. Quebec had the highest per capita total, $\$ 1017$, with Nova Scotia only a tenner and two toonies behind, at $\$ 1003$.

CIHI attributes these variations to factors such as differences in drug subsidy programs, differences in health care delivery and differences in population health. Growth of per capita spending also varied across the country, and was particularly low in British Columbia $(1.8 \%)$ and Ontario $(2.3 \%)$, the two provinces that have taken the strongest measures to reduce the prices of generic drugs.

Internationally, Canada ranks high in total drug expenditure per capita. In 2008, only the United States spent more per person on drugs among the 25 countries in the Organisation for Economic Co-operation and Development. In terms of portion of drug costs covered by public funds, Canada (38.4\%) was somewhere near the bottom, ahead of only Poland $(38.3 \%)$, the United States (32.8\%) and Mexico (20.1\%). In the United Kingdom, by contrast, a whopping $84.7 \%$ of drug costs came out of public coffers.

"International data has to be interpreted with a little bit of caution," sug- gests Gaucher. "Countries have very different health care delivery models."

The implications of the Canadian data are also open to interpretation, if not a total mystery in some areas, as the report acknowledges in a section called "What We Don't Know." Does spending on drugs decrease hospitalization or affect spending in other areas of health care? This isn't known. Perhaps more importantly, data on drug spending doesn't indicate "whether increases in total drug expenditure negatively or positively affect overall health outcomes." - Roger Collier, CMAJ

CMAJ 2011. DOI:10.1503/cmaj.109-3893 